\title{
Phonological Phrases in Xhosa (Southern Bantu) ${ }^{1}$
}

\author{
Sabine Zerbian \\ ZAS Berlin
}

This paper investigates how syntax and focus interact in deriving the phonological phrasing of utterances in Xhosa, a Bantu language spoken in South Africa. Although the influence of syntax on phrasing is uncontroversial, a purely syntactic analysis cannot account for all the data reported for Xhosa by Jokweni (1995). Focus influences the phrasing in that it inserts a phonological phrase-boundary after the focused constituent. This generalization can account for the variation found in the phrasing of adverbials.

The findings are dealt with in an OT-based framework following Truckenbrodt's work on Chichewa $(1995,1999)$ which is extended to the phrasing of adjuncts.

\section{Introduction}

Work on vowel length in Chi Mwi:ni (Kisseberth and Abasheikh 1974) or on tone assignment in Xiamen Chinese (Chen 1987), to name just two, brought evidence for the assumption that certain phenomena are sensitive to prosodic domains, and that these domains stand in a certain relationship to syntactic domains. In both languages, Chi Mwi:ni and Xiamen Chinese, the correct domains can be predicted by aligning the right edges of syntactic XPs with prosodic boundaries.

In this paper I re-examine the interrelation of syntactic and phonological structure in phrasing in Xhosa based on the data provided in Jokweni (1995), a Southern African Bantu language spoken in South Africa. I follow the standard view that an approach in terms of prosodic structure domains defined in relation to syntactic structure provides a general rule for domain-related phonological processes such as the lengthening of vowels in penultimate position. However, reference to syntax alone in defining prosodic domains encounters problems with respect to the syntactic status of adverbs. Instead I show that focus has to

1 I thank Hubert Truckenbrodt, Caroline Féry, David Odden and Laura J. Downing for discussing aspects of this work and valuable feedback. 
be taken into consideration when accounting for phonological phrases in Xhosa. This view is in accord with research done for other Bantu languages for which focus is claimed to have considerable influence on phonological phrasing (e.g. Kanerva 1990, Truckenbrodt 1995, 1999, Jokweni 1995). In order to express the influence focus has on the phrasing derived by syntax, I will formalize the findings in an OT-based approach following Truckenbrodt $(1995,1999)$ who has accounted for the influence of focus on phrasing in Chichewa. Furthermore, I will extend his theory which has accounted for argument structures in Chichewa to adjunct structures in Xhosa.

The paper is organized as follows: In section 2 I will present phonological processes that apply in certain prosodic domains as evidence for the need of phonological phrases in Xhosa. In section 3 I present the data on phrasing in Xhosa and discuss how Jokweni (1995) accounts for the observed boundaries. In section 4 I show that focus has a systematic influence on phrasing in Xhosa. Section 5 deals with the theoretical treatment of conflicts of syntax and prosody following Selkirk $(1986,1995)$ and Truckenbrodt $(1995,1999)$. In section 6 the analysis for Xhosa is presented. It will be shown that the theory has to be extended to the phrasing of adjunct structures in order to account for the Xhosa data. The paper closes with a summary in section 7 .

The paper presents a preliminary approach to these aspects in Xhosa as it is solely based on data available in the literature. Since the goal of the available literature is different from the goals persued in this paper, revealing data on e.g. the phonology-syntax interface are missing in the original literature or negative data are not supplied. The issues touched upon on here will be persued in further research with mother tongue speakers.

\section{Phonological Processes at phonological phrase boundaries}

Evidence for pP-boundaries in Xhosa comes from two phonological processes that indicate right edges of phonological phrases (Jokweni 1995). One is the lengthening of the vowel in penultimate position, the other process involves tonological changes. Both processes will be dealt with in turn.

\subsection{Vowel lengthening}

Jokweni (1995) shows that the process of Penultimate Vowel Lengthening in Xhosa provides evidence for the existence of the Phonological Phrase $(\mathrm{pP})^{2}$.

2 I use a somewhat different notation for the prosodic units (pP, iP) in order to avoid confusion with the syntactic constituents (PP, IP). 
In Xhosa as in many other Bantu languages there is no vowel length contrast in words. All vowels appear as short vowels. Nevertheless, depending on its position in the sentence an underlying short vowel can surface as long in the penultimate syllable of a word. Literature on the phonology of Bantu languages suggest that the long vowel in penultimate position is the result of a boundary-related phonological process. For Xhosa, Jokweni (1995) proposes that this process of penultimate vowel lengthening applies at the right edge of a $\mathrm{pP}$. The size of the $\mathrm{pP}$ varies with respect to the number of constituents it comprises, as the examples in (1) show (pP-boundaries are marked by parentheses, acute marks high tones):

(1) pPs in Xhosa, Jokweni (1995: 26f, 31)
(a) (íntaaka) $)_{\mathrm{pP}}$
(intákaana) $)_{\mathrm{pP}}$
(ba-vúl' íncwaadí) $)_{\mathrm{pP}}$
,bird“
SC-open book 9
(b) (bá-ya-yi-vúúl' $)_{\mathrm{pP}}(\text { íncwaadí) })_{\mathrm{pP}}$, They are opening the book. SC-YA-OC9-open book 9
(c) (íncwaadí) $)_{\mathrm{pP}}$ (bá-ya-yi-vúúla) $)_{\mathrm{pP}}$, As for the book, they open it.' book SC-YA-OC9-open

The examples in (1) show variations in pP-boundaries that Jokweni (1995) uses to argue for the necessity of the prosodic unit pP. The example in (1b) shows that Penultimate Lengthening cannot be related to the fact that a word appears at the boundary of an utterance as could be imagined from the examples in (1a). The variation in length of the penultimate vowel of the verb given in (1b) shows that the lengthening process is related to other factors than utterance finality as also utterance-medial words can be lengthened. Jokweni (1995) proposes that lengthening is sensitive to pPs and that it appears at pP-boundaries. Consequently, a pP-boundary intervenes between the verb and object in (1b) and between the object and verb in (1c). The rule of Penultimate Lengthening is given in (2).

3 The abbreviations used in the glosses are the following:
SC subject concord
OC object concord with numbers indicating noun classes
YA morpheme of the short form of the present tense
nouns are given followed by their noun class number
bold printing indicates focus 
(2) Penultimate Lengthening in Xhosa, Jokweni (1995: 25)

$\varnothing \rightarrow \mathrm{V} / \mathrm{CV}_{\mathrm{pP}}$

The rule in (2) states that a short vowel becomes long in penultimate position of a phonological phrase.

\subsection{Word-final High Tone Deletion}

With respect to tonal evidence Jokweni's work (1995) provides examples that show that the rule of word-final $\mathrm{H}$ deletion only applies pP-medially. When occurring at the edge of $\mathrm{pP}$ a final high tone of a word is kept, as shown in the examples in (3).

(3) Word-final H deletion, Jokweni (1995: 117, 128)

(a) (kuutyá) $)_{\mathrm{pP}}$ 'to eat'

(b) (bá-tya ínyaama) $)_{\mathrm{pP}} \quad$ 'They eat meat.'

SC-eat meat

(c) (bá-ya-yii-tyá) $)_{\mathrm{pP}}(\text { ínyaama })_{\mathrm{pP}}$ 'They eat it, meat.'

SC-YA-OC9-eat meat 9

Example (3a) shows that the verb has a high tone on the final syllable when it appears in isolation. This high tone is not realized when the verb form appears phrase-medially, as shown in (3b). In (3c), the right-dislocated object constitutes its own $\mathrm{pP}$. Therefore the $\mathrm{H}$ appears on the verb as it ends a $\mathrm{pP}$.

Both phonological processes, vowel lengthening and word-final $\mathrm{H}$ deletion, are diagnostics for pP-boundaries in Xhosa. I will only refer to lengthening phenomena in the following as they are easily indicated in the transcription by a doubled vowel.

\section{$3 \quad$ Phrasing in Xhosa: Jokweni's proposal (1995)}

In the preceding section I have shown that a right pP-boundary can be detected in Xhosa by a lengthened penultimate vowel. This section discusses the relation between syntax and phrasing in Xhosa. On the basis of the data presented in this section, Jokweni (1995) proposes a language-specific algorithm in order to account for the derivation of phonological phrase boundaries in Xhosa. Jokweni (1995: 52ff) shows that algorithms proposed as universal in the literature (Selkirk (1980), Selkirk (1986), and Nespor \& Vogel (1986)) do not account for the data in Xhosa, nor that language-specific algorithms (McHugh (1990), Chen (1987), Hale \& Selkirk (1987)) can be transferred to Xhosa. Selkirk's proposal 
$(1980,1986)$ will be discussed in section 5 in more detail. In the following I will have a look at the phrasing of VO- and of $\mathrm{V}(\mathrm{O}) \mathrm{Adv}$-structures and how they are accounted for in Jokweni (1995).

\subsection{The phrasing of VO-structures}

First, complement structures will be considered, that display the basic word order (SVO), i.e. that object(s) follow the verb. Consider the data in (4).

(4) Phrasing in Xhosa, Jokweni (1995: 31f)
(a) (abántwana ba-kháb' íbhóóla $)_{\mathrm{pP}}$
children SC-kick ball
'Children are kicking the ball.'
(b) (ba-vúl íncwaadí) $)_{\mathrm{pP}}$
SC-open book
'They open the book.'

The sentences in (4) show simple transitive sentences ((4a) with, (4b) without explicit subject). They all display the basic word order SVO, in which the complements directly follow the verb. Furthermore, they all have in common that they are phrased into one single $\mathrm{pP}$ as indicated by the lengthened vowel only in penultimate syllable of the last word in the sentence. In the cases in (4), the $\mathrm{pP}$ is coextensive with the utterance. A pP-boundary is inserted at the right edge of the utterance. The syntactic structure following Haegemann $(1991)^{4}$ is illustrated in (5).

(5) Phrasing in Xhosa, Jokweni (1995: 38f)
(a) (u-lím’ úmbóóna) $)_{\mathrm{pP}}$
SC-cultivate maize
'He/ she cultivates maize.'

4 The syntactic structure above the VP is a matter of controversy in Bantu languages. Whereas Jokweni (1995) and Spuy (1993) adopt the generative framework, Bresnan (1994) and Morimoto (2000) e.g. do not assume two functional phrases above the VP. However, it shall not matter here, how the superior syntactic phrase is labelled. It is only important that it is no lexical phrase but a functional phrase. 
(b) syntactic structure following Jokweni $1995: 39^{5}$

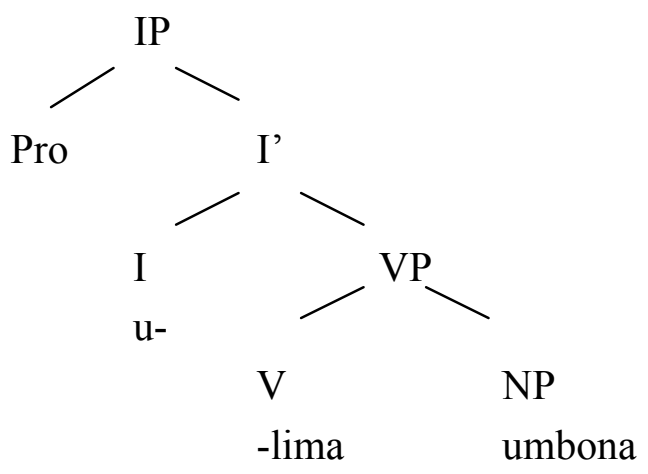

In (5), a transitive verb surfaces with a substantival complement. Evidence for the complement status is that it is obligatory (*Uliima.) and that no constituent can intervene between the verb and the object (see also van der Spuy (1993) for a similar argument).

In order to account for this phrasing in Xhosa, Jokweni proposes the algorithm in (6) for the construction of pPs.

(6) Preliminary version of the PP-algorithm for Xhosa (Jokweni 1995:24)

A head X of a syntactic phrase XP phrases with all elements within the maximal projection XP.

The algorithm in (6) assumes that all postverbal constituents in (5) are phrased together with the verb in a VP. It can therefore correctly account for the observed phrasing in $(5)^{6}$.

Now consider cases where a comparable sentence is divided into more than one $\mathrm{pP}$, as shown in (7).

(7) Phrasing in Xhosa, Jokweni (1995: 31f, 55)

(a) (bá-ya-yi-vúúl' $)_{\mathrm{pP}}(\text { íncwaadí })_{\mathrm{pP}}$

SC-YA-OC9-open book 9

'They open it, as for the book.'

(b) (ba-m-ník' úkuuty') ${ }_{\mathrm{pP}}$ (úmaamá) $)_{\mathrm{pP}}$

SC-OC1-give food mother 1

'They give her food, mother.'

5 The substantival object can also be expressed by an object marker which appears left to the verb as in (u-ya-wu $\mathrm{i}_{\mathrm{i}}$-liima $\mathrm{pro}_{\mathrm{i}}$ )- 'He/ she cultivates it.'. In this case Jokweni assumes that the position of the substantival NP is occupied by an object pro. I will not consider these cases here.

6 The phrasing of the subject will be dealt with separately in section 6.4. 
In the examples in (7) the sentence is divided into two pPs. The syntax of the construction in (7) is examplified in (8).

(8) Phrasing in Xhosa, Jokweni (1995: 39f)

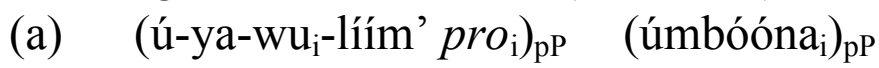

SC-YA-OC-cultivate maize

'He/ she cultivates it, maize.'

(b) syntactic structure from Jokweni (1995: 40)

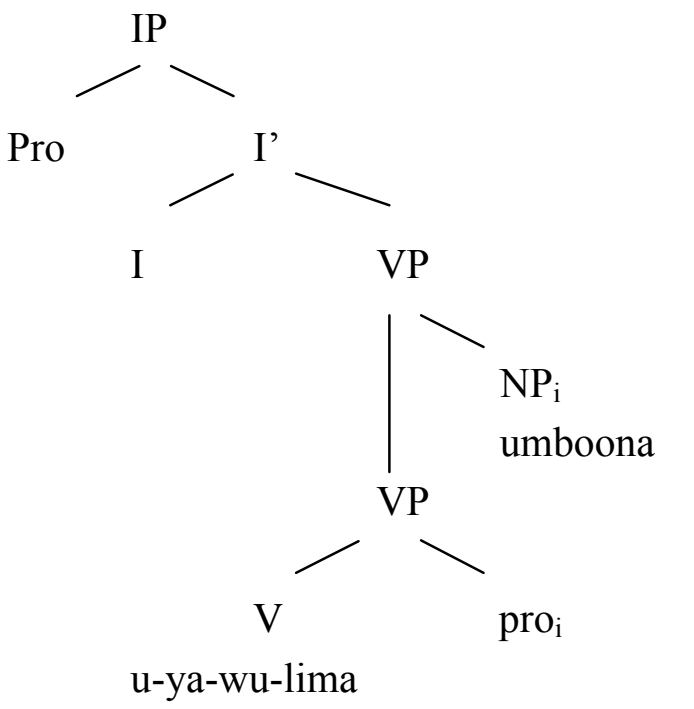

In (8), a transitive verb surfaces with both a pronominal marker and a substantival NP. The object is optionally included in the sentence as the object pronominal already fulfills the function of the complement of the transitive verb (with respect to pro see footnote 5). The substantival object is not part of the VP but is adjoined to the VP instead ${ }^{7}$. A comparable analysis has also been proposed by Bresnan (1987) for similar data in Chichewa, and by Spuy (1993) for Zulu. Besides the optionality of the object NP and the presence of the object marker there is further evidence for the adjunction of the NP outside the VP: With adjoined object NPs movement and intervening constituents are possible. The examples in (9) illustrate that syntactic structures as in (8) allow a wider range of word order variations than the basic SVO order.

(9) Phrasing in Xhosa, Jokweni (1995: 49, 50, 47)

(a) (íncwaadí) $)_{\mathrm{pP}}(\text { bá-ya-yi-vúúla })_{\mathrm{pP}}$ book 9 SC-YA-OC9-open

'The book, they open it.'

7 Jokweni assumes the adjoined object to be in the upper VP projection in order to be in line with the phrase structure as outlined in Haegemann (1991: 44). The question where the dislocated NP is adjoined to is of no importance at the moment. 
(b) (Lé ndooda $)_{\mathrm{pP}}(\text { abántwaana })_{\mathrm{pP}}$ (í-ya-ba-béétha $)_{\mathrm{pP}}$ this man children 2 SC-YA-OC2- beat

'This man, children, he beats them.'

(c) (bá-ya-yi-vúúl' $)_{\mathrm{pP}}$ (ébusuuk' $)_{\mathrm{pP}}(\text { íncwaadí) })_{\mathrm{pP}}$

SC-YA-OC9-open at-night book 9

'They open it at night, the book.'

The examples in (9) all show word orders that are only possible when the object NP cooccurs with an object concord on the verb. (9a) shows the object leftdislocated, preceeding the subject, $(9 \mathrm{~b})$ left-dislocated following the subject, and (9c) right-dislocated with an adverbial intervening between verb and object.

Jokweni (1995) accounts for the separate phrasing by modifying the phrasing algorithm, as in (10).

(10) Final PP-algorithm for Xhosa as proposed by Jokweni (1995: 24)

(a) a head X of a syntactic phrase XP phrases with all elements within the maximal projection XP provided those elements are not adjoined.

(b) Adjuncts or adjoined elements each constitute a pP of their own.

To phrase it differently, Jokweni (1995) proposes that a head is phrased together with all elements within a maximal projection. Adjuncts to a maximal projection are phrased separately.

Jokweni's (1995) analysis similarly applies to ditransitive constructions, as shown in (11).

(11) Phrasing of ditransitive verbs in Xhosa, Jokweni (1995: 55)

(ba-ník' úmam' úkuutyá) ${ }_{\mathrm{pP}}$

SC-give mother food

'They give mother food.'

In (11), the whole sentence is contained in one pP. Both objects are complements to the verb and are phrased within the maximal projection of the verb. The derivation of pP-boundaries by the algorithm in (10) makes Jokweni's analysis superior to earlier analyses such as Nespor \& Vogel (1986), and Selkirk $(1980,1986)$, as in Xhosa both object NPs phrase together. Algorithms by both Nespor \& Vogel (1986), and Selkirk $(1980,1986)$ predict a separate phrasing of the second object (see demonstration and detailed discussion of Selkirk (1980, 1986) in section 5).

To sum up, in the cases in (4) the object is complement to the verb and is phrased together into one VP, and consequently, according to (10), into one pP. In the cases in (7), the object NP is represented by an object marker on the verb, 
and the optional object (or objects) is (are) no longer complement but adjunct to VP. As the head V is phrased with all elements in its VP except adjoined elements, the adjoined object NPs constitute their own pP. We will have a look at the phrasing for adjuncts in the next section.

\subsection{Phrasing of $V-(O)$-Adv-structures}

In Xhosa, adverbials appear at the right sentence periphery following the verb and its objects in basic word order. Consider (12) to see the variation with respect to phrasing in adverbials.

(12) Phrasing of adverbials, Jokweni (1995: 60, 64)

(a) (ba-líma ngo-Mqgibéèlo $)_{\mathrm{pP}}$

SC-plough on-Saturday

'They plough on Saturday.'

(b) (ba-yá-liima $)_{\mathrm{pP}} \quad(\text { ngoMqgibéèlo })_{\mathrm{pP}}$

SC-YA-plough on-Saturday

'They plough on Saturday.'

In (12a), the adverbial phrases together with the verb as can be seen from the missing long vowel in penultimate position in the verb. In (12b), the sentence is split up into two pPs. The first $\mathrm{pP}$ ends after the verb, and the adverbial is phrased in a separate $\mathrm{pP}$.

A syntactic account assumes two different syntactic structures for the two different phrasings in (12), see e.g. Jokweni (1995). Adverbs are therefore assigned ambigious syntactic structure, sometimes inferring being phrased together with the verb, sometimes inferring being phrased separately. This is problematic as there is no further evidence that supports such an ambigious syntactic status in minimal pairs as $(12)^{8}$. Adverbials are always optional (except for verbs that subcategorize for an adverbial) and can consequently be dropped without the sentence becoming ungrammatical.

A purely syntactic approach to the difference in phrasing weakens the classical notions of complements and adjuncts. In the following section, I will show that the data in (12) can be accounted for when focus is taken into consideration. With regard to the syntactic position of adverbials discussed in this section, I will assume that adjuncts are optional by definition as

8 Jokweni (1995) claims that the distribution of the verbal particle -ya- shows further evidence for the ambigious status of adverbs. According to Jokweni (1995) the absence of the verbal particle $-y a$ - in (12a) indicates that the verb subcategorizes for an overt complement. But see Zerbian (2003) for a different analysis concerning the distribution of $-y a$ - which makes no reference to grammatical relations but to pPs instead. 
obligatoriness means being subcategorized for by the verb which adverbials are not. Furthermore, I will assume that also optional elements can be phrased within the VP (see (13)). So far there is no evidence for a structural difference between complements and adjuncts in Xhosa.
(a)
adjuncts
(b)
complements
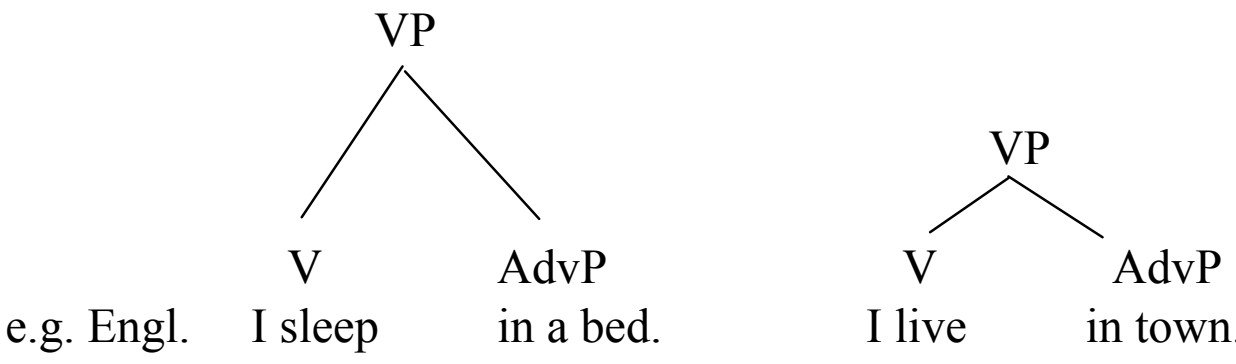
I live in town.

In (13a) the adverbial phrase is an adjunct as the verb sleep does not subcategorize for a local adverbial. The verb live in (13b), however, does categorize for a local adverbial.

\section{$4 \quad$ Prosodic marking of focus}

In the preceding section I have shown that a purely syntactic analysis of the data on phrasing in Xhosa assigns adverbials an undesireable ambigious status. In this section I want to show that taking focus into consideration can explain the phrasing of adverbials. The influence of focus was mentioned in Jokweni (1995:14) but was not integrated in his algorithm for phonological phrasing in Xhosa.

In 4.1. I present some theoretical background on focus, in 4.2. I will present the Xhosa data in a way that show the influence of focus.

\subsection{Focus}

In Western European languages, intonational accent is the main way focus is expressed, while focus position and focus morphology play more minor roles. However, like most of the Bantu languages Xhosa is a tone language, where intonational accent is not reported to correlate with focus. Instead, tone languages are reported to use alternative means of expressing focus: nonintonational prosodic phrasing, focus morphemes on the verb and particles, and fixed clause position.

In this paper I will concentrate on the use of non-intonational prosodic phrasing as a means of expressing focus, although also morpho-syntactic changes are of importance as can be easily seen from the examples. For the explanation of the Xhosa data presented so far a distinction of two different 
kinds of focus is necessary: sentence focus (or all-new/ wide focus) and term focus (narrow focus). Sentence focus means that all the information conveyed in the sentence is new to the hearer. Term focus means that only a piece of information is new to the hearer. Focus structures can be easily and unambigiously elicited by means of questions. The interrogative elicits the new information, so that in the answers the constituent corresponding to the interrogative word is automatically placed in focus. Chomsky (1971: 199) and Jackendoff (1972: 230) express the general rule that the question and answer should have equivalent focus structures. Wide focus turns up in answers to questions such as 'What happened?', or 'What are they doing?' where all the information given is new. Narrow focus appears in answers to Wh-questions.

\subsection{Influence of focus in Xhosa}

The focus structure of the examples presented so far has been elicited by Jokweni (1995) by means of questions. Rearranging the Xhosa data according to the kind of focus they express show a striking difference in phrasing. The sentences in (14) all display wide focus/ sentence focus (as indicated by the question).

(14) Phrasing under wide focus, Jokweni (1995: 31, 47, 60, 67, 74)
(a) (ba-vúl' íncwaadí) $)_{\mathrm{pP}} \quad$ (Q: What are they doing?)
SC-open book
'They are opening a book.'
(b) (ba-ník' úmam' úkuutyá) $)_{\mathrm{p}}$
SC-give mother food
'They give the mother food.'
(c) (ba-líma ngo-Mqgibéèlo $)_{\mathrm{pP}}$
SC-plough on-Saturday
'They plough on Saturday.'
SC-cry badly
'They cry badly.'
(d) (ba-líla kákuubí) $)_{\mathrm{pP}}$
(e) (ndi-tyél' ínyam' émbizééni) ${ }_{\mathrm{pP}}$ SC-eat meat in.pot
'I eat meat in the pot.'

Syntactically, the sentences in (14) display the unmarked word order SVO and are phrased together in one $\mathrm{pP}$. This is true for all constructions considered so far: (14a) shows a transitive verb, (14b) a ditransitive verb, (14c) a verb followed by a temporal, (14d) by a modal adverbial, and finally (14e) a verb 
followed by an object and a local adverbial. In terms of focus one can conclude that in sentences displaying wide focus the VP is phrased into one $\mathrm{pP}$.

The data in (15) show that it is due to narrow focus that the phrasing is split up.

\begin{tabular}{|c|c|}
\hline (a) & $\begin{array}{ll}\text { Phrasing under narrow focus, Jokweni }(1995: 65,69,64,1 \\
\begin{array}{ll}\text { (bá-zaku-liima) })_{\mathrm{pP}} & \text { (ngezáándla) })_{\mathrm{pP}} \\
\text { SC-Fut-plough } & \text { by-hands }\end{array}\end{array}$ \\
\hline (b) & $\begin{array}{l}\text { 'They are going to plough (not do something else) by hands.' } \\
\left.\text { (bá-ya-fudúúka) })_{\mathrm{pP}} \text { (ngoLwésihláánu) }\right)_{\mathrm{pP}} \\
\text { SC-YA-emigrate on-Friday }\end{array}$ \\
\hline (c) & $\begin{array}{ll}\text { 'They do emigrate on Friday.' } \\
\begin{array}{ll}\text { (ba-yá-liima) })_{\mathrm{pP}} & \text { (ngoMqgibéèlo })_{\mathrm{pP}} \\
\text { SC-YA-plough } & \text { on-Saturday }\end{array}\end{array}$ \\
\hline (d) & $\begin{array}{l}\text { 'They plough on Saturday.' } \\
\left.\left.\text { (ba-ya-kuutya) })_{\mathrm{pP}} \text { (ukuutya) }\right)_{\mathrm{pP}} \text { (ngezaandla) }\right)_{\mathrm{pP}} \\
\text { SC-YA-eat food by hands }\end{array}$ \\
\hline & 'They do eat food by hands.' \\
\hline
\end{tabular}

The data in (15) show that narrow focus induces a phrase boundary following the focused constituent. In (15a-d), the verb is focused in contrast to the sentences in (14). Note, that there is no evidence for a change in syntactic structure. A phrase-boundary occurs after the focused verb. The examples show that focus influences the phrasing in that the focused constituent triggers the insertion of a pP-boundary. One can further observe that in verb forms in the Present Tense (15b-d) an additional morpheme -ya- occurs on the verb. This morpheme has been analysed as a focus marker, marking predicate focus on the verb (Güldemann 1996). The status of this morpheme is unclear (for a semantically oriented analysis for comparable facts in Sotho see Kosch (1988), for a syntactic analysis see Spuy (1993), for a prosodic analysis see Zerbian (2003)). However, the insertion of prosodic boundaries also occurs in other tenses than the Present Tense, see (15a), justifying a more general analysis.

To sum up, the data in (14) and (15) show that a given sentence differs in phrasing according to its information structure, i.e. the constituents that are in focus. Whereas in (14) under wide focus all postverbal elements are phrased together, in (15) where the verb is in focus, the phrasing is split up. However, focus alone cannot predict the phrasing neither. Consider the examples in (16). 
(16) Phrasing in Xhosa, Jokweni (1995: 48, 49)

(a) (ba-kháb' íbhóól' $)_{\mathrm{pP}}$ (ébusuuk') $)_{\mathrm{pP}}(\text { abántwaana })_{\mathrm{pP}}$

SC-kick ball at night children 2

'They kick the ball, at night, as for children.'

(b) (íncwaadí) ${ }_{\mathrm{pP}}(\text { ébusúuku })_{\mathrm{pP}}$ (bá-ya-yi-vúúla) $)_{\mathrm{pP}}$

book 9 at night SC-YA-OC 9-open

'As for the book, at night, they open it.'

Though focus determines the phrase boundary after the focused argument ball in (16a), the phrase boundary after the following adjunct is not determined by focus but by syntax as the following subject is right-dislocated. Similarly, in the example in (16b) syntax alone determines the phrasing of the adjunct at night as it is not in focus but left-dislocated for other pragmatic reasons. Therefore, in the examples in (16) morphosyntactic changes play a crucial role and determine the phonological phrasing. Consequently, it is the interaction of pragmatic (focus) and syntactic (dislocation) considerations that determines phonological phrasing in Xhosa.

In the following I will account for the competing forces of syntax and focus in phrasing by presenting Truckenbrodt's $(1995,1999)$ approach to comparable data on phrasing in Chichewa (Kanerva 1990). Acknowledging the influence focus has on phrasing correctly predicts the pP-boundaries in Chichewa.

\section{$5 \quad$ Conflicting constraints in syntax and prosody}

In section 3 I have shown that the phrasing in Xhosa cannot be accounted for by reference to syntax alone, instead I have shown in section 4 that focus is necessary to be taken into consideration as well.

Truckenbrodt's $(1995,1999)$ work investigates the relation of syntax, focus, and phrasing in Chichewa, a Bantu language spoken in Malawi, basing his analysis on original work by Kanerva (1990) who showed that phrasing is crucially determined by focus in Chichewa. In his work on the relation of syntactic XPs and prosodic structure Truckenbrodt $(1995,1999)$ shows that patterns of phrasing can better be understood when the syntax-prosody mapping is formalized in terms of ranked and violable constraints as in the framework of Optimality Theory (Prince and Smolensky 1993). He improves on Selkirk's $(1986,1995)$ end-based theory of the syntax-prosody relation in accounting for data in Tohono O'odham, Kimatuumbi, and Chichewa, which have not been accounted for in the end-based theory.

In this section I want to develop an analysis for the data in Xhosa presented in section 3 in the OT-framework following the work of Truckenbrodt 
$(1995,1999)$ for Chichewa. I want to show how the account proposed here can account for the phrasing in Xhosa. I will first show the cases whose phrasing is syntax-based such as the complement structures, also in connection with focus. I will then proceed to the crucial cases of adverbials and show that the OT-based analysis that considers focus can account for the phrasing if extended to adverbials. Finally, I will present the phrasing of the subject in Xhosa, and show that further research is needed to provide independent evidence for the syntactic structure of the subject.

\subsection{The prosody-syntax interface}

Based on the observations that certain phenomena are sensitive to prosodic domains and that these domains stand in a certain relationship to syntactic domains (e.g. Kisseberth \& Abasheikh (1974), Chen (1987)), Selkirk (1986) proposes a universal theory of phrasing which formulizes the edge alignment of phonological phrases with syntactic XPs. This theory is called end-based theory as it inserts a prosodic phrase boundary at the end of syntactic phrases. Selkirk (1995) reformulates her former analysis in the format of General Alignment (McCarthy \& Prince 1993). The constraint for aligning syntactic XPs with prosodic boundaries in order to derive prosodic domains following Selkirk (1995) reads as in (17).

(17) Align-XP,R: Align (XP, R; P, R) (following Truckenbrodt (1999))

For each XP there is a $\mathrm{P}$ such that the right edge of $\mathrm{XP}$ coincides with the right edge of $\mathrm{P}$.

Align-XP,L: Align (XP, L; P, L)

For each XP there is a $\mathrm{P}$ such that the left edge of XP coincides with the left edge of $\mathrm{P}$.

According to Selkirk (1995), every language makes a paradigmatic choice between right- or left alignment. In the following I will restrict myself to rightalignment of syntactic phrases with prosodic boundaries as this will be the relevant parameter for the analysis of Chichewa and Xhosa.

In his work on phonological phrases and their relation to syntax, focus, and prominence Truckenbrodt $(1995,1999)$ introduces the constraint WRAP-XP. He claims that this constraint exists besides Selkirk's edge alignment, and that its relation to the alignment constraints can explain the variation in phrasing found in the languages of the world. Moreover, it can explain the data on phrasing found in Kimatuumbi and Chichewa which have not been accounted for before. The constraint WRAP-XP reads as in (18).

(18) WRAP-XP

Each XP is contained in a phonological phrase. 
One effect of the constraint in (18) is that it reduces prosodic structure. In contrast to ALIGN (XP, R; P, R) as stated by Selkirk (1995) it only ensures that every XP is contained in one $\mathrm{pP}$, but it does not require every $\mathrm{XP}$ to be aligned with a prosodic boundary, thus constituting its own phrase. As WRAP-XP is claimed to exist besides the alignment constraint, these two constraints are in conflict and the stronger influence of one constraint or the other yields at different phrasings. The different phrasings are shown in (19) and (20).

(19) Predicted phrasing when ALIGN is dominant (following Selkirk 1995)
(a) $\left[\begin{array}{ll}\mathrm{XP}_{2} & \mathrm{X}_{1}\end{array}\right]_{\mathrm{XP} 1}$

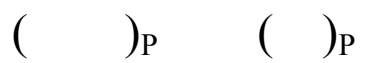
(c) $\quad\left[\begin{array}{lll}\mathrm{X}_{1} & \mathrm{XP}_{2} & \mathrm{XP}_{3}\end{array}\right]_{\mathrm{XP1}}$
(b) $\quad\left[X_{1}\right.$
$\left.\mathrm{XP}_{2}\right]_{\mathrm{XP} 1}$
)$_{\mathrm{P}}$

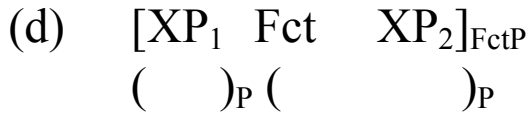

(20) Predicted phrasing when WRAP-XP is dominant (following Truckenbrodt 1999)
(a)
$\left[\mathrm{XP}_{2}\right.$
$\left.\mathrm{X}_{1}\right]_{\mathrm{XP} 1}$
)$_{\mathrm{P}}$
(c) $\quad\left[X_{1}\right.$
$\left[\begin{array}{lll}\mathrm{X}_{1} & \mathrm{XP}_{2} & \mathrm{XP}_{3}\end{array}\right]_{\mathrm{XP} 1}$
(
)$_{\mathrm{P}}$
(b) $\left[\begin{array}{ll}\mathrm{X}_{1} & \mathrm{XP}_{2}\end{array}\right]_{\mathrm{XP} 1}$
(d) $\left[\begin{array}{lll}\mathrm{XP}_{1} & \text { Fct } & \mathrm{XP}_{2}\end{array}\right]_{\mathrm{FctP}}$

When comparing the different predictions in terms of phrasing made by the dominance of one of the two constraints we can see that in some cases they coincide (b, d) but in others they differ (a, c). (20a, c) shows that WRAP-XP is a structure-preventing constraint as it reduces the number of $\mathrm{pPs}$ in these constructions.

The examples from Chichewa and Xhosa illustrate the effects of the two constraints in the following section.

\section{The case of Xhosa}

\subsection{Phrasing under wide focus}

As shown by the examples in (14) in Xhosa sentences show a strong tendency to be phrased into one $\mathrm{pP}$ in the pragmatically unmarked case. Under wide focus, complements are phrased into one phrase in transitive and ditransitive constructions. Tableau 1 shows the phrasing of simple transitive structures in Xhosa (example 14a, repeated as (21)). 
(21) (ba-vúl' íncwaadí) $)_{\mathrm{pP}}$

(Q: What are they doing?)

SC-open book

'They are opening a book.'

Tableau 1 : Basic phrasing in Xhosa

\begin{tabular}{|c|c|c|c|}
\hline$[\mathrm{V} \mathrm{NP}]_{\mathrm{VP}}$ & WRAP-XP & ALIGN-XP, R & NonReC \\
\hline a. ()$P$ & & & \\
\hline b. $\quad(\quad)(\quad) P$ & $* !$ & & \\
\hline c. $\quad(() \mathrm{P}) \mathrm{P}$ & & & $* !$ \\
\hline
\end{tabular}

The tableau in (1) lists possible candidates for the phrasing of simple transitive structures. Candidate a is the winner: The whole VP is phrased into one phonological phrase. As shown in $(19 b, 20 b)$ this can be accounted for by either ranking WRAP-XP above ALIGN-XP, R or vice versa since the transitive structure violates none of these constraints. Simple transitive structures do not provide the necessary data to decide between these two rankings. However, tableau 1 shows that NONREC, a constraint against recursive structures, must be ranked high enough to prevent the corresponding candidate (c) to emerge as the winning candidate. As recursive structures have been shown not to be allowed in Chichewa (Truckenbrodt 1995, 1999) and as there is no evidence for recursive structures in Xhosa neither, candidates displaying recursive structures will not be considered in the following tableaux ${ }^{9}$.

The case of double object constructions is the crucial case that motivates the constraint WRAP-XP for Chichewa and also for Xhosa.

(a) Chichewa (Kanerva 1990)

(tinapatsa mwana njiinga) $)_{\mathrm{pP}}$
we-gave child

'We gave the child a bicycle.'

(b) Xhosa (Jokweni 1995)

(ba-ník' úmam' úkuutyá) ${ }_{\mathrm{pP}}$

SC-give mother food

'They give the mother food.'

In Xhosa as in Chichewa, ditransitive structures like (22) are phrased into one phonological phrase. They thereby provide evidence that a constraint like WRAP-XP is ranked above ALIGN-XP,R as both Xhosa and Chichewa prefer the

9 Neither will the constraint EXHAUSTIVITY (Selkirk 1995: 443) be considered that requires that phrasing on every prosodic level is exhaustive. As words are always parsed into some $\mathrm{pP}$, no candidates with unparsed words will be included in the following tableaux. 
whole VP being wrapped in one pP instead of phrasing each XP individually. The latter phrasing would be predicted by the end-based approach (cf. also 19c, 20c).

The analysis for examples as in (22) is shown in tableau 2.

Tableau 2: Basic phrasing in Chichewa and Xhosa

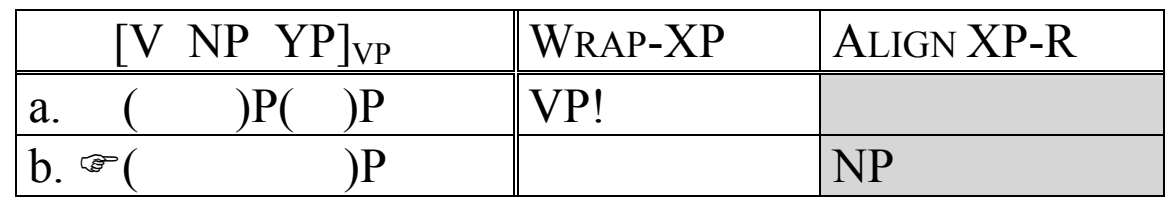

Candidate a in which the VP is phrased into two separate phonological phrases is ruled out by violation of the high-ranked constraint WRAP-XP that favours the VP being wrapped into one phonological phrase. Candidate $b$ emerges as winner. Though it violates ALIGN XP-R by not aligning the first NP with a phonological phrase boundary the violation is not fatal as ALIGN XP-R is ranked below the other relevant constraints.

The phrasing of structures containing an adverbial in Xhosa can be captured by the same account. Relevant examples already mentioned in the data exposition in section 3, 4 are repeated in (23).

(23) Xhosa, Jokweni $(1995: 60,67,74)$
(a) (ba-líma ngo-Mqgibéèlo $)_{\mathrm{pP}}$
SC-plough on-Saturday
'They plough on Saturday.'
(b) (ba-líla kákuubí) ${ }_{\mathrm{pP}}$
SC-cry badly
'They cry badly.'
(c) (ndi-tyél' ínyam' émbizééni) $)_{\mathrm{pP}}$ SC-eat meat in.pot
'I eat meat in the pot.'

The account for the observed phrasing is illustrated in tableau 3 for example (23c).

Tableau 3 : Basic phrasing in Xhosa

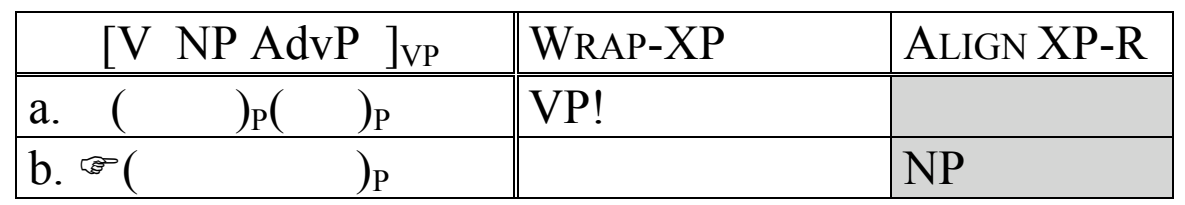


Similarly to complements, candidate a in which the VP is phrased into two separate phonological phrases is ruled out by violation of the high-ranked constraint WRAP-XP that favours the VP being wrapped into one phonological phrase. Candidate $\mathrm{b}$ emerges as winner. Though it violates ALIGN XP-R by not aligning the object NP with a phonological phrase boundary the violation is not fatal as ALIGN XP-R is ranked below the relevant constraint.

The discussion of the phrasing of transitive, ditransitive and structures containing an adverbial under wide focus in Xhosa supports the need for a constraint like WRAP-XP as proposed by Truckenbrodt $(1995,1999)$. Neither the end-based approach nor the relation-based approach (Nespor \& Vogel 1986) can account for the observation that under narrow focus the verb is phrased into one phonological phase together with the constituents that follow it.

\subsection{Phrasing under narrow focus}

As shown in section 4, narrow focus leads to syntactic changes in complement structures in Xhosa. The object(s) representing old information are moved out of the VP, leaving an object clitic on the verb ${ }^{10}$. The relevant examples are repeated in (24).

(24) Xhosa, Jokweni (1995: 31f, 55, 78)

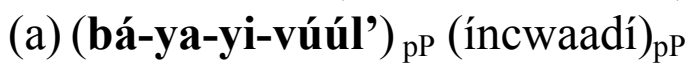

SC-YA-OC9-open book 9

'They open it, as for the book.'

(b) (ba-m-ník' úkuuty' ${ }_{\mathrm{pP}}$ (úmaamá) $)_{\mathrm{pP}}$

SC-OC1-give food mother 1

'They give her food, mother.

(c) (ndi-ya-m-phékeel' $)_{\mathrm{pP}} \quad$ (úmaam' $)_{\mathrm{pP}}(\text { ínyaama })_{\mathrm{pP}}$

SC-YA-OC1-cook.for mother 1 meat

'I cook for her, mother, meat.'

In (24a) the verb is focused in a simple transitive structure. The object clitic appears on the verb and the verb is phrased separately. In (24b), the patient NP is focused in a ditransitive structure. The object clitic of the benefactive NP appears on the verb and the benefactive NP appears outside the VP. In (24c), the verb is focused in a ditransitive structure. As there is only one slot in the TMA-

10 The question which phrase the dislocated NPs are adjoined to is not important for the analysis here. Spuy (1993) assumes that they are adjoined to IP, Jokweni (1995) for Xhosa, and Truckenbrodt $(1995,1999)$ for Chichewa assume that they are adjoined to the VP. Truckenbrodt $(1995: 235)$ shows that only the deepest embedded VP is subject to WRAP-XP, not the doubled VPs resulting from the adjoinment of dislocated phrases. 
template of the verb to accommodate an object clitic the object clitic of the beneficiary NP appears on the verb. However, both objects appear outside the $\mathrm{VP}$, as indicated by prosody and word order.

The analysis for these structures is given in tableau 4. Tableau 4 examplifies the structure in (24c).

Tableau 4 : Phrasing under narrow focus in Xhosa

\begin{tabular}{|c|c|c|c|}
\hline & {$\left[\mathrm{V}_{\mathrm{FOC}}\right]_{\mathrm{VP}}[\mathrm{NP}][\mathrm{PP}]$} & WRAP-XP & ALIGN XP-R \\
\hline a. & ()$_{\mathrm{P}}$ & & VP!, NP \\
\hline & $\left(\begin{array}{ll}{ }_{\mathrm{P}} & ( \\
\end{array}\right.$ & & NP! \\
\hline & $\begin{array}{lllll}( & )_{\mathrm{P}} & ( & )_{\mathrm{P}}( & )_{\mathrm{P}}\end{array}$ & & \\
\hline
\end{tabular}

As the objects are moved out of the VP, they are no longer under the influence of WRAP-XP. As they are not headed by a shared lexical category the conditions for WRAP-XP to apply are not met. Consequently they are phrased separately in order to maximally satisfy ALIGN-XP, R, as does the winning candidate $\mathrm{c}$.

As has been demonstrated in tableau 4, in double object constructions with the verb in focus, the phrasing is determined by syntax in Xhosa and can be accounted for by the constraints WRAP-XP and ALIGN-XP, R. A parallel analysis along these lines applies for the other examples in (24).

The effect of focus on argument structures reveals interesting variation among Bantu languages. In Xhosa, it results in morphosyntactic changes whereas a different structure is found in Chichewa. In Chichewa, a pP-boundary is inserted after the focused constituent without changes in syntactic structure. Examples are given in (25).

(25) Phrasing in double object constructions in Chichewa (Kanerva 1990)

(a) Q: What did they do in Mavuto's house?

(anagoona) $)_{\mathrm{pP}} \quad(\text { mnyumba ya mavuuto })_{\mathrm{pP}}$

they-slept in-house of Mavuto

'They slept in the house of Mavuto.'

(b) Q: What did he hit with the rock?

(anamenya nyuumba) $)_{\mathrm{pP}}$ (ndi mwaala $)_{\mathrm{pP}}$

he-hit house with rock

'He hit the house with the rock.'

Evidence for the emerging pP-boundaries right after the focused constituent is provided by the lengthened vowels in penultimate position (see Kanerva 1990). The effect of boundary insertion after a focused constituent is accounted for by 
the constraint ALIGN-FoC which is given in (26) following Truckenbrodt (1995, 1999).

Align-FoC $=$ Align (FoC, R; P, R)

'Each focused constituent is right-aligned with a p-boundary.'

A constraint similar to (26) has also been proposed for other languages (such as Bengali, Japanese, and Korean). How ALIGN-FoC is integrated into the theory is illustrated in tableau 5 for Chichewa.

Tableau 5: Phrasing under narrow focus in Chichewa

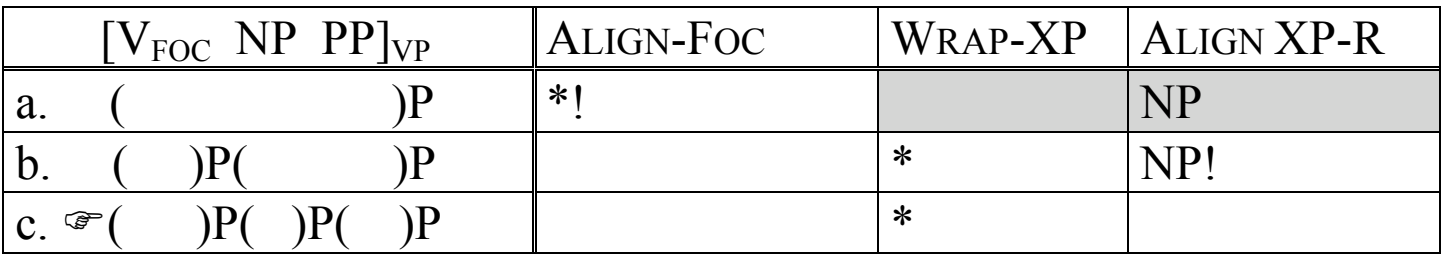

In contrast to Xhosa, unfocused objects in Chichewa are not moved out of the VP. They therefore fall under the influence of the constraint WRAP-XP (for the need of WRAP-XP in Chichewa see the examples in (22a)). By ranking ALIGNFOC above WRAP-XP the influence of WRAP-XP is neutralized. Note that this assumption only holds if WRAP-XP is not a gradient constraint, i.e. if WRAP-XP does not differentiate between how many phrase boundaries split up the VP. Because of the neutralization of WRAP-XP the constraint ALIGN-XP has crucial influence on the phrasing of the complements and will therefore prefer each complement in a separate phonological phrase, as in the winning candidate in c.

\subsection{Analysis of adverbial structures}

As shown in the preceding section, there is variation in languages concerning the question if they show purely phonological reflects of information structure as in Chichewa or (morpho-)syntactic reflects of information structure as in $\mathrm{Xhosa}^{11}$. In the last section the discussion was mainly restricted to arguments. In this section I want to show that the same constraint responsible for prosodic changes in argument structures in Chichewa, namely AligN-Foc, can account for focus in adverbial structures in Xhosa. Adverbial constructions in Xhosa show a crucial influence of focus on phrasing in Xhosa. The data have been

11 The question that is not adressed here is what triggers the morphosyntactic changes in Xhosa. One could speculate if the same constraint, namely ALIGN-Foc, is responsible for the observed changes. 
presented in examples $(12,15)$ already. Remember that for a sentence displaying wide focus the same analysis applies as for transitive sentences, see tableau 3.

The same mechanism as in Chichewa complement structures applies to Xhosa adverbial structures when the verb is narrowly focused. Relevant examples are provided in (27).

(27) Xhosa, Jokweni $(1995: 64,65,69)$
(a) (ba-yá-liima $)_{\mathrm{pP}} \quad$ (ngoMqgibéèlo $)_{\mathrm{pP}}$
SC-YA-plough on-Saturday
'They plough on Saturday.'
(b) (bá-zaku-liima) $)_{\mathrm{pP}} \quad(\text { ngezáándla })_{\mathrm{pP}}$
SC-Fut-plough by-hands
'They are going to plough (not do something else) by hands.'
(c) (bá-ya-fudúúka) $)_{\mathrm{pP}}(\text { ngoLwésihláánu })_{\mathrm{pP}}$
SC-YA-emigrate on-Friday
'They do emigrate on Friday.'

For the analysis compare tableau 6 for adverbials under verb focus in Xhosa with tableau 5 for complement structures under verb focus in Chichewa.

Tableau 6 : Phrasing under narrow focus in Xhosa

\begin{tabular}{|ll|l|l|l|}
\hline & {$\left[\mathrm{V}_{\mathrm{FOC}} \text { AdvP }\right]_{\mathrm{VP}}$} & ALIGN-FOC & WRAP-XP & ALIGN XP-R \\
\hline a. $\quad(r) \mathrm{P}$ & $* !$ & & \\
\hline b. & $(\quad) \mathrm{P}(\mathrm{f}) \mathrm{P}$ & & $*$ & \\
\hline
\end{tabular}

Although the winning candidate $b$ violates the constraint WRAP-XP this violation is not fatal. Candidate a that satisfies this constraint is ruled out because it violates the higher-ranked constraint ALIGN-Foc.

In tableau 6 I expand Truckenbrodt's $(1995,1999)$ theory in order to account for focus in adjunct structures. Assuming that adjuncts are part of the VP his analysis can account for the phrasing of adverbs in unmarked structure but also under focus. AlIGN-FOC is necessary in order to account for the prosodic structure as there is no independent evidence for the syntactic structure.

To sum up, in the preceding section I have presented Truckenbrodt's approach to account for the Chichewa data. Since Selkirk's end-based theory does not account for the data, he proposes an additional constraint WRAP-XP that can explain why in double object constructions no phrase boundary is inserted after the first complement. Nevertheless, if WRAP-XP is neutralized e.g. by means of focus the influence of ALIGN-XP, R shines through by phrasing individually each complement that follows a focused verb. 


\subsection{Data on subjects}

A further refinement of the end-based theory was initiated by Selkirk \& Shen (1990) in their work on Shanghai Chinese. It is also integrated into the format of Selkirk (1995). The basic idea is that lexical phrases (and their projections) and functional phrases (and their projections) behave differently in terms of relating syntactic and prosodic structure. Truckenbrodt (1999) calls this the Lexical Category Condition.

(28) Lexical Category Condition (LCC, Truckenbrodt 1999)

Constraints relating syntactic and prosodic categories apply to lexical syntactic elements and their projections, but not to functional elements and their projections.

The LCC predicts that alignment constraints will apply to lexical categories such as NPs, VPs, PPs, and APs, but not to functional syntactic categories such as DPs, IPs, or CPs. Consequently, the constraint Align (XP, R; P, R) stated by Selkirk (1995) will exclude the insertion of prosodic phrase boundaries at edges of functional syntactic phrases.

For the discussion of Chichewa and Xhosa data in this section functional phrases at a higher syntactic level are of importance. Since it is controversial how many functional phrases above the VP exist in Bantu languages (see e.g. Spuy (1993) for IP and CP in Zulu; Bresnan (1994) for only one functional phrase), I assume the more minimal view and only consider one higher syntactic phrase, called IP here.

This section deals with problems encountered when expanding Truckenbrodt's analysis also to the phrasing of the subject in Xhosa. The data on subject phrasing reveal a basic difference between Xhosa and Chichewa. Whereas in Chichewa the subject is phrased separately from the verbal complex, the data on subject phrasing in Xhosa show that in the pragmatically unmarked case it is phrased together with the verbal complex. Examples are given in (29).

(29) Phrasing of the subject in Xhosa (Jokweni 1995: 31, 50)
(a) (abántwana ba-kháb' íbhóóla $)_{\mathrm{pP}}$
children SC-kick ball
'Children are kicking the ball.'
(b) (Lé ndod' i-béth' abántwaana) $)_{\mathrm{pP}}$ this man SC-beat children
'This man beats children.'


Under the premises that the subject and verb complex is unified in a functional phrase, the IP in standard generative grammar, the phrasing in (29) cannot be accounted for in neither the end-based theory nor the OT-based analysis. Selkirk predicts a pP-boundary after every XP, Truckenbrodt's analysis ends in the same result as the subject and verb complex are unified in a functional category, thus WraP-XP does not apply and ALIGN-XP, R shows its influence. Only the parametric approach (Hale \& Selkirk (1987) on Papago) can account for the phrasing in (29) given that the choice is such that only functional categories trigger the insertion of pP-boundaries (this will not be persued here further).

I will have a closer look at the crucial point that makes the OT-based approach fail the analysis. As mentioned above, the premise that subject and verb phrase are unified in the functional phrase IP predicts a pP-boundary following the subject, as WRAP-XP does not apply and ALIGN-XP,R right-aligns every XP with a pP-boundary. There are two different ways to save the analysis for the Xhosa data; either to change the ranking in an OT-based account, or to revise the syntactic assumptions. Both possibilities will be presented and discussed in turn.

\subsubsection{Reranking of *P-Phrase}

A further deviation in the analysis by Truckenbrodt that distinguishes it from its antecedent by Selkirk is the assumption that alignment is not subject to language-specific parametrization (left-/ right-alignment), but to differences in ranking. Besides the two alignment constraints shown in (17) every language has an additional constraint that can render one or both of the alignment constraints inactive. This additional constraint is given in (30).

*P-PHRASE

Avoid p-phrases altogether.

Depending on the ranking of the constraint in (30) with respect to the alignment constraints the winning candidate will either show a uniform direction of alignment or no alignment at all. The data on phrasing in Xhosa presented so far suggest that under wide focus there is a single pP. Neither subjects nor objects trigger the insertion of a pP-boundary. An example that supports this generalization is given in (31). The sentence displays no sentence-medial pPboundaries although it has a higly complicated and long structure. 
(31) Xhosa, Jokweni (1995: 98)

(si-fún' úkú-xélel' abántwana úkubama-bá-ty' ínyaama) $)_{\mathrm{pP}}$

SC-want to-tell children that HORT-SC-eat meat

'We want to inform the children that they should eat meat.'

The observation that in pragmatically unmarked structures pPs are avoided can be expressed by ranking the constraint *P-PHRASE high in an analysis of the Xhosa data. The possibility to avoid pPs in a given language is implied in OTbased approaches (typologies by different rankings of the constraints). Such an analysis works well for pragmatically unmarked transitive and ditransitive structures, and naturally makes the right predictions concerning the phrasing of the subject.

The relevant data from Xhosa are given in (32).

(32) Phrasing of the subject in Xhosa (Jokweni 1995: 31, 50)

(a) (abántwana ba-kháb' íbhóóla $)_{\mathrm{pP}}$

children SC-kick ball

'Children are kicking the ball.'

(b) (Lé ndod' i-béth' abántwaana) ${ }_{\mathrm{pP}}$

this man SC-beat children

'This man beats children.'

Tableau 7: Phrasing of the subject in Xhosa

\begin{tabular}{|l|l|l|l|l|}
\hline \multicolumn{2}{|c|}{$\left[\mathrm{S}[\mathrm{V} \mathrm{XP}]_{\mathrm{VP}}\right]_{\mathrm{IP}}$} & *P-PHRASE & WRAP-XP & ALIGN XP-R \\
\hline a. ( & P & $*$ & & $* *$ \\
\hline b. $(\mathrm{)}) \mathrm{P}(\quad) \mathrm{P}$ & $* * !$ & & $*$ \\
\hline
\end{tabular}

Both candidates $a$ and $b$ satisfy the constraint WRAP-XP since WRAP-XP only requires lexical XPs to be phrased into one phonological phrase. Therefore it requires the VP in the structures in (32) to be phrased together. The subject, however, constitutes a functional phrase which does not fall in the scope of WRAP-XP. On the contrary, ALIGN XP-R becomes relevant here which requires every XP to be phrased separately. Candidate a violates this constraint once more than candidate $b$, exactly because the subject is not phrased separately. Therefore, *P-PHRASE must be ranked above ALIGN XP-R in order to assure candidate a as the winning candidate.

However, the analysis proposed in tableau 7 based on the phrasing of the subject runs into problems when faced with the data on verb focus in ditransitive constructions, as will be shown in tableau 8 . To remind the reader of the relevant structures an example is repeated in (33). 
(33) Xhosa, Jokweni (1995)

(ndi-ya-m-phékeel' $)_{\mathrm{pP}} \quad(\text { úmaam' })_{\mathrm{pP}}(\text { ínyaama })_{\mathrm{pP}}$

SC-YA-OC1-cook.for mother 1 meat

'I cook for her, mother, meat.'

Tableau 8: Phrasing of ditransitive structures in Xhosa

\begin{tabular}{|c|c|c|c|c|c|c|}
\hline \multicolumn{3}{|c|}{$\left[\mathrm{S} \mathrm{V}_{\mathrm{FOC}}\right]_{\mathrm{VP}}[\mathrm{XP}][\mathrm{XP}]$} & \multirow{2}{*}{$\begin{array}{l}\text { AllGN- } \\
\text { FOC } \\
* !\end{array}$} & \multirow{2}{*}{$\begin{array}{l}* \text { P-PHRASE } \\
*\end{array}$} & \multirow[t]{2}{*}{ WRAP-XP } & \multirow{2}{*}{$\begin{array}{l}\text { ALIGN XP- } \\
\mathrm{R} \\
* *\end{array}$} \\
\hline ( & & )P & & & & \\
\hline b. $\approx($ & )P( & $\mathrm{P}$ & & $* *$ & & $*$ \\
\hline c. $\quad($ & ) $\mathrm{P}($ & $\mathrm{P}$ & & $* * * !$ & & \\
\hline
\end{tabular}

Tableau 8 shows that ranking *P-Phrase high but still below ALIGN-FoC predicts pP-boundaries induced by focus but no other pP-boundaries. It correctly excludes candidate a where no focus-induced boundary occurs. Under this ranking, however, the observable additional pP-boundary following the first dislocated complement remains unexplained, as in candidate c which is the truthful winner. The wrong candidate is chosen as the winner (indicated by the bomb).

Turning the constraint $*$ P-PHRASE into a non-gradient (=categorical) constraint (McCarthy 2003) does not save the analysis. Non-gradedness of a constraint means that it can only be violated once. Therefore in tableau 9 every candidate having more than one $\mathrm{pP}$ violates the constraint *P-PHRASE only once, independent of the number of pPs it actually displays.

Tableau 9: Phrasing of ditransitive structures in Xhosa

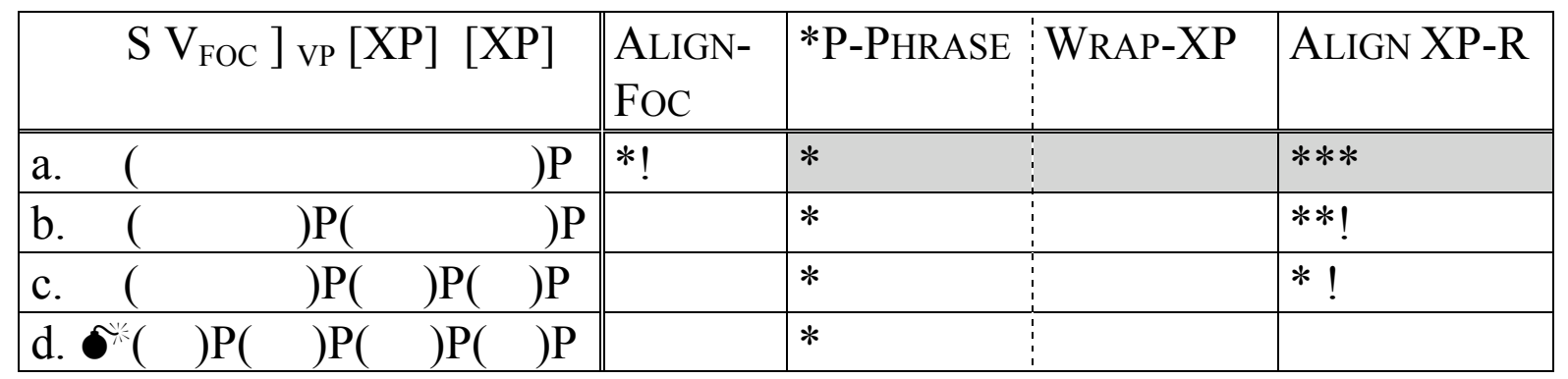

Although candidate $\mathrm{b}$ is ruled out in the analysis in tableau 8 because it crucially violates ALIGN-XP,R, the right output $\mathrm{c}$ is ruled out too. Candidate $\mathrm{d}$ satisfies the constraints best when phrasing the subject separately. Though the necessary data are missing, the prediction based on the data available is, that this is not the case in Xhosa. The subject is only phrased separately when in focus (see section 6.5.). 
Dominance of the constraint *P-PHRASE is consequently not a possible solution as it only allows pP-boundaries induced by focus. The data from Xhosa, however, show evidence that pP-boundaries show up for syntactic reasons. Therefore, the next possibility that is going to be discussed is assuming a change in syntactic structure.

\subsubsection{Subject-in-VP- hypothesis}

Data on subject phrasing that are parallel to Xhosa have been discussed by Hale \& Selkirk (1987) for Papago. The solution offered by Hale \& Selkirk (1987) is that in Papago, subject and verb are both constituents of the VP. Their parametric approach to phrasing provides the possibility for a language to set the phrasing parameters in such a way that either functional or lexical phrases trigger the insertion of pP-boundaries. For Papago they assume lexical categories to trigger the insertion of pP-boundaries. Consequently, the VP would trigger a pP-boundary. Truckenbrodt (1995) adopts this analysis when discussing the Papago data in his framework. As subject and objects all belong to VP, WRAP-XP applies and favours wrapping the whole complex into one pP. This is exactly what happens in the Xhosa data. Why not accept such an analysis for Xhosa?

Whereas Papago and Chichewa are unrelated languages, Chichewa and Xhosa belong to the same language family, namely Bantu languages. There might be independent evidence to assume the subject-in-VP hypothesis for Papago. For Chichewa, Truckenbrodt (1999:227) assumes at least such a complex structure of the VP as proposed by Larson (1988). This means that the subject is base-generated in Spec-V position where it gets its theta-role assigned by the verb as it is within the minimal m-command. Here, the subject is internal to VP. But under subject-verb agreement the subject is moved out of the VP to the next higher syntactic phrase, which is a functional phrase.

To sum up this section, the OT-based analysis makes the right predictions when assuming the subject to be in VP-internal position. However, as long as there is no independent evidence for the syntactic structure regarding the subject in Xhosa it seems arbitrary to determine the syntax of the subject based on phrasing alone.

\subsection{Subject and focus}

In the preceding subsections I have shown that the phrasing of the subject in constructions displaying wide focus cannot be accounted for yet. However, under narrow focus on the subject the same generalizations apply as with verbs 
in focus. A pP-boundary is inserted after the focused constituent. The data are given in (34).

(34) Xhosa, Jokweni (1995: 27, 32)

(a) (abántwana ba-kháb' íbhóóla) $)_{\mathrm{pP}}$

children SC-kick ball

'Children are kicking the ball.' (What is going on?)

(b) (abántwaana) $)_{\mathrm{pP}}$ (ba-kháb' íbhóóla $)_{\mathrm{pP}}$

children 2 SC-kick ball

'The children kick the ball.'

The sentences in (34) show a near minimal pair that differs only in focus and pP-boundaries. Note that there is no evidence to assume a cleft-like construction in example (34b) although cleft constructions are often used in Bantu languages to express subject focus. (34b) supports the view that also in the case of subject focus a boundary is inserted after the focused constituent.

Tableau 10 shows that the effect of focus on the phrasing of subjects can be accounted for by the analysis presented so far.

Tableau 10: Phrasing under subject focus in Xhosa

\begin{tabular}{|l||l|l|l|}
\hline$\left[\left[\mathrm{S}_{\mathrm{FOC}}[\mathrm{V} \text { AdvP }]_{\mathrm{VP}}\right]_{\mathrm{IP}}\right.$ & ALIGN-FOC & WRAP-XP & ALIGN XP-R \\
\hline a $(\quad)) \mathrm{P}$ & $* !$ & & $*$ \\
\hline b. ${ }^{*}(\mathrm{r}) \mathrm{P}(\quad) \mathrm{P}$ & & & \\
\hline
\end{tabular}

Though candidate $a$ is preferred under wide focus, candidate $b$ is the winner for narrow focus on the subject. This can be accounted for by ranking the constraint ALIGN-FOC high which is crucially violated by candidate a.

This section has shown the problems that arise in connection with the phrasing of the subject. Further research and more data are needed in order to account for the relation of syntax and prosody with regard to the subject.

\section{$7 \quad$ Summary}

In this paper I have shown how syntax and focus interact in deriving the phonological phrasing of utterances in Xhosa. Although the influence of syntax on phrasing is uncontroversial, a purely syntactic analysis cannot account for the data. I have shown how one could argue for a systematic influence of focus. The influence is such that it inserts a pP-boundary after the focused constituent 
unless there is one triggered by syntax already. This generalization can account for the variation found in the phrasing of adverbials.

I have formalized the findings in an OT-based framework in order to theoretically account for the impact focus-related constraints have on phrasing as derived by syntax-related constraints. In order to account for the variation found in the phrasing of adverbials I have transferred Truckenbrodt's analysis (1995, 1999) to the phrasing of adjuncts. Furthermore, I have pointed out problems in connection with the phrasing of the subject.

\section{References}

Bresnan, J. (1994) Locative inversion and the architecture of universal grammar. Language 70 (1): 72-131.

Bresnan, J. \& S. A. Mchombo (1987) Topic, pronoun, and agreement in Chichewa. Language 63 (4): 741-782.

McCarthy, J. (2003) OT-constraints are categorical. Phonology 20: 75-138.

Chen, M. Y. (1987) The syntax of Xiamen tone sandhi. Phonology Yearbook 4: 109-149.

Chomsky, N. (1971) Deep structure, surface structure, and semantic interpretation. Semantics: An Interdisciplinary Reader in Philosophy, Linguistics, and Psychology. D.D. Steinberg \& L. A. Jakobovits (eds.) Cambridge, Cambridge University Press: 183216.

Güldemann, T. (1996) Verbalmorphologie und Nebenprädikation im Bantu. Bochum, Universitätsverlag Dr. N. Brockmeyer.

Haegemann, L. (1991) Introduction to Government \& Binding Theory, Blackwell.

Hale, K. \& E. Selkirk (1987) Government and tonal phrasing in Papago. Phonology Yearbook 4: $151-183$.

Jackendoff, R. (1972) Semantic Interpretation in Generative Grammar. Cambridge (Mass.), Massachusetts Institue of Technology.

Jokweni, M. W. (1995) Aspects of Isixhosa Phrasal Phonology. Doctoral thesis, UrbanaChampaign, University of Illinois.

Kanerva, J. (1990) Focus and Phrasing in Chichewa Phonology. New York: Garland Publishing.

Kisseberth, C. W. \& M. I. Abasheikh (1974) Vowel length in Chi-Mwi:ni- A Case Study of the Role of Grammar in Phonology. Papers from the Parasession on Natural Phonology. A. Bruck et al. (eds.), CLS: 193-209.

Kosch, I. M. (1988) Imperfect tense -a' of Nothern Sotho revisited. South African Journal of African Languages 8 (1): 1-6.

Larson, R. (1988) On the double object construction. Linguistic Inquiry 19: 335-391.

McCarthy, J. \& A. Prince (1993) Generalized Alignment. Yearbook of Morphology 1993. G. Booij \& J. v. Marle (eds.). Dordrecht, Kluwer: 79-153.

McHugh, B. D. (1990) The Phrasal Cycle in Kinvunjo Chaga Tonology. In: The PhonologySyntax Connection. S. Inkelas \& D. Zec (eds.). Stanford, CSLI.

Morimoto, Y. (2000) Discourse Configurationality in Bantu Morphosyntax, Doctoral thesis, Stanford University.

Nespor, M. and I. Vogel (1986) Prosodic Phonology. Dordrecht, Foris Publications. 
Selkirk, E. (1980) On Prosodic Structure and its Relation to Syntactic Structure. Bloomington, Indiana: Indiana University Linguistics Club.

Selkirk, E. (1986) On Derived Domains in Sentence Phonology. Phonology Yearbook 3: 371405.

Selkirk, E. (1995) The prosodic structure of function words. In: J. Beckman, L. Wlash Dickey \& S. Urbanczyk (eds.). Amherst, GLSA, University of Massachusetts. Papers in Optimality Theory: 439-469.

Selkirk, E. \& Shen, T. (1990) Prosodic Domains in Shanghai Chinese. In: The PhonologySyntax Connection. S. Inkelas \& D. Zec (eds.). Stanford, CSLI: 313- 337.

Spuy, A. v. d. (1993) Dislocated noun phrases in Nguni. Lingua 90: 335-355.

Truckenbrodt, H. (1995) Phonological phrases: Their relation to syntax, focus, and prominence. Doctoral thesis, Massachussetts Institute of Technology.

Truckenbrodt, H. (1999) On the Relation between Syntactic Phrases and Phonological Phrases. Linguistic Inquiry 30 (2): 219-255.

Zerbian, S. (2003) Morphological Marking of Phonological Phrase Boundaries in Xhosa. Proceedings of Prosodic Interfaces, Nantes: 209-214. 